\section{AB0335 EFFECT OF TOTAL KNEE ARTHROPLASTY ON MEDICATION IN PATIENTS WITH RHEUMATOID ARTHRITIS}

K. Harigane ${ }^{1,2}$, Y. Mochida ${ }^{1}$, K. Kumagai ${ }^{2}$, K. Ishii ${ }^{1}$, Y. Miyamae ${ }^{1}$, N. Mitsugi ${ }^{3}$, H. Choe ${ }^{2}$, A. Nagaoka ${ }^{2}$, Y. Inaba ${ }^{2}$, T. Saito ${ }^{2} .{ }^{1}$ Center for Rheumatic Diseases, Yokohama City University Medical Center; ${ }^{2}$ Orthopaedic Surgery, Yokohama City University; ${ }^{3}$ Orthopaedic Surgery, Yokohama City University Medical Center, Yokohama, Japan

Background: Several studies reported that development of phaemacological treatment for rheumatoid arthritis (RA) contributed to decreased number of orthopaedic surgery. [1-3] Surgical treatment is, however, still required in many cases, and the impact of orthopaedic surgery on disease activity remain unclear. Objectives: This study evaluated the effect of total knee arthroplasty (TKA) with capsulosynovectomy on chenges of disease activity and medication in patients with RA.

Methods: Seventy-seven serial patients with RA (61 female and 16 male) who underwent primary TKA with more than one year of follow-up were retrospectively reviewed to assess postoperative disease activity and drug administration. The mean age at the time of surgery was 68.3 years old. The disease activity of RA was measured using Disease Activity Score in 28 Joints (DAS28). To evaluate the effects of medication on preoperative and postoperative disease activity, outcomes at before surgery and one year after surgery were separately investigated following two groups; patients who were treated with the same or reduced medication (same group) and patients who were administered with additional or altered medication (change group).

Results: Seventy-two patients $(97.3 \%)$ were administered with at least one DMRDs before or after surgery. The mean dose of methotrexate (MTX) was $7.7 \mathrm{mg} /$ week before surgery and $8.0 \mathrm{mg} /$ week after surgery respectively. The number of patients who were treated with biological DMARDs was increased after surgery (17 patients vs.21 patients), however there was not significant differences. RA disease activity was significantly decreased in DAS28-CRP one year after surgery. (3.9 vs. $2.7, p<0.01$ ) As for difference of the disease activity in same and change groups, DAS28-CRP was significantly decreased after surgery. (same group; 3.7 vs. $2.5, p<0.01$, change group; 4.5 vs. $3.2, p<0.01$ ) DAS28-CRP in change group was significantly higher both before and after surgery compared with those in same group. $(p<0.01)$

Conclusions: TKA with capsulosynovectomy improves disease activity after surgery in patients with RA. Based on the results, patients with higher disease activity before surgery required further medication after surgery.

\section{References:}

[1] Dusad A et al. Impact of Total Knee Arthroplasty as Assessed Using PatientReported Pain and Health-Related Quality of Life Indices: Rheumatoid Arthritis Versus Osteoarthritis. Arthritis Rheumatol. 2015; 67: 2503-11.

[2] Yano K et al. Effect of total knee arthroplasty on disease activity in patients with established rheumatoid arthritis: 3-year follow-up results of combined medical therapy and surgical intervention. Mod Rheumatol. 2010; 20: 452-7.

[3] Oh $\mathrm{K}$ et al. Effects of surgical intervention on disease activity of rheumatoid arthritis: cases of surgery for rheumatoid arthritis of the lower limbs treated with biologics. Mod Rheumatol. 2014; 24: 606-11.

Disclosure of Interest: None declared

DOI: 10.1136/annrheumdis-2017-eular.2416

\section{AB0336 MAGNETIC RESONANCE IMAGING-ASSESSED SYNOVIAL AND BONE CHANGES IN HAND AND WRIST JOINTS OF RHEUMATOID ARTHRITIS PATIENTS}

K.A. Lee, S.-H. Min, T.-H. Kim, S.-H. Lee, H.-R. Kim. Internal Medicine, Konkuk University Medical Center, Seoul, Korea, Republic Of

Background: Magnetic resonance imaging (MRI) is a sensitive and useful method for the detection of synovitis and joint destruction in rheumatoid arthritis (RA) patients. However, the patterns of MRI-detected bone erosion, bone marrow edema (BME), synovitis, and tenosynovitis have received insufficient attention.

Objectives: Therefore, this study evaluated the patterns of bone erosion, BME, synovitis, and tenosynovitis, and calculated the RA-MRI score (RAMRIS) of patients with RA at the carpal and metacarpophalangeal (MCP) joints using MRI.

Methods: MRI datasets from 43 RA patients were analyzed. All patients had undergone MRI of one wrist. In addition, 36 patients had MCP joint images taken, and 3 had also received MRI of the contralateral wrist and MCP joints. The MR images were evaluated for bone erosion, BME, and synovitis in consensus by 2 blinded readers according to the OMERACT RA-MRI score (RAMRIS). The MRIdetected tenosynovitis was evaluated based on Haavardsholm's tenosynovitis score.

Results: The capitate, lunate, triquetrum, and hamate bones were the most common sites of erosion and BME and showed the highest RAMRIS erosion and BME scores. Moreover, MRI-detected tenosynovitis was present in $78.3 \%$ of all patients with RA, and the extensor compartment 4 and flexor digitorum profundus and superficialis were frequently affected.

Conclusions: This study identified the distribution and prevalence of MRIdetected bone erosion, BME, synovitis, and tenosynovitis of the wrist and MCP joints in RA patients. The patterns of the MRI-detected abnormalities may help to select sites for the application of MRI protocols in clinical trials and practice.

\section{References:}

[1] Ejbjerg B, McQueen F, Lassere M, Haavardsholm E, Conaghan P, O'Connor P, et al. The EULAR-OMERACT rheumatoid arthritis MRI reference image atlas: the wrist joint. Annals of the rheumatic diseases. 2005;64 Suppl 1:i23-47.

[2] Ostergaard M, Edmonds J, McQueen F, Peterfy C, Lassere M, Ejbjerg B, et al. An introduction to the EULAR-OMERACT rheumatoid arthritis MRI reference image atlas. Annals of the rheumatic diseases. 2005;64 Suppl 1:i3-7.

[3] Conaghan P, Bird P, Ejbjerg B, O'Connor P, Peterfy C, McQueen F, et al. The EULAR-OMERACT rheumatoid arthritis MRI reference image atlas: the metacarpophalangeal joints. Annals of the rheumatic diseases. 2005;64 Suppl 1:i11-21.

[4] Haavardsholm EA, Ostergaard M, Ejbjerg BJ, Kvan NP, Kvien TK. Introduction of a novel magnetic resonance imaging tenosynovitis score for rheumatoid arthritis: reliability in a multireader longitudinal study. Annals of the rheumatic diseases. 2007;66(9):1216-20.

Acknowledgements: The author(s) declared no potential conflicts of interest with respect to the research, authorship, and/or publication of this article.

Disclosure of Interest: None declared

DOI: 10.1136/annrheumdis-2017-eular.1507

\section{AB0337 BIOLOGIC THERAPY IN SEVERE PERIPHERAL ULCERATIVE KERATITIS (PUK). MULTICENTER STUDY OF 27 PATIENTS}

L. Domínguez-Casas ${ }^{1}$, V. Calvo-Río ${ }^{1}$, O. Maíz ${ }^{2}$, A. Blanco ${ }^{2}$, E. Beltrán ${ }^{3}$, L. Martínez-Costa ${ }^{4}$, M. Alvarez del Buergo ${ }^{5}$, E. Rubio-Romero ${ }^{6}$, D. Díaz-Valle ${ }^{7}$, R. López-González ${ }^{8}$, A. García Aparicio ${ }^{9}$, A. Juan Mas ${ }^{10}$, N. Palmou ${ }^{1}$, M. González-Gay ${ }^{1}$, R. Blanco ${ }^{1} .{ }^{1} \mathrm{HUMV}$, Santander; ${ }^{2} \mathrm{H}$, Donostia; ${ }^{3} \mathrm{H} ;{ }^{4} \mathrm{H}$ Peset, Valencia; ${ }^{5} \mathrm{H} ;{ }^{6} \mathrm{H}$ Río Carrión, Palencia: ${ }^{7} \mathrm{H}$ San Carlos, Madrid; ${ }^{8} \mathrm{C}$ Hospitalario, Zamora; ${ }^{9} \mathrm{H}$, Toledo; ${ }^{10} \mathrm{H}$ S Llàtzer, P Mallorca, Spain

Background: Peripheric Ulcerative Keratitis (PUK) is a severe inflammation that may lead to ocular perforation. PUK may be primary or associated with systemic conditions. Treatment is based on corticosteroids and conventional systemic immunosuppressive drugs.

Objectives: To evaluate biologic therapy in cases with severe and refractory PUK. Methods: Multicenter study from 9 hospitals. Patients presented inadequate response or intolerance to conventional therapy with corticosteroids and at least 1 systemic traditional immunosuppressive drug.

The main outcome measures were visual acuity, signs of inflammation, progression to corneal thinning, central keratolysis and ocular perforation. Comparisons were made between baseline and 1st week, 1st month, 6th month and 1st year. Statistical analysis was performed using the software STATISTICA (StatSoft). Results were expressed as mean $\pm S D$ for variables with a normal distribution, or as median [IQR] when they were not normally distributed. The comparison of continuous variables was performed using the Wilcoxon test and categorical variables with chi-square test.

Results: We studied 27 patients/35 affected eyes ( 7 men/20 women), mean age, $57.2 \pm 16.3$ years (range 28-89). PUK was primary in 1 case whereas in the 26 remaining cases, the underlying diseases were Rheumatoid Arthritis (RA) $(n=19)$,

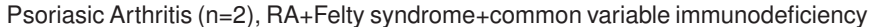
$(n=1)$, Behçet Disease $(n=1)$, Type I diabetes mellitus $(n=1)$, granulomatous polyangiitis $(n=1)$ and microscopic polyangiitis $(n=1)$. They received the following topical therapy: corticosteroids $(n=18)$, antibiotics $(n=17)$, lubricants $(n=18)$, autologous serum $(n=11)$, topical cyclosporin $2 \%(n=11)$ and topical tacrolimus $0.03 \%(n=1)$. Besides oral corticosteroids and before the onset of the biologic therapy they had received iv pulses of methylprednisolone $(n=8)$, methotrexate (16), oral doxycycline (9), azathioprine (3) and ascorbic acid (2). Moreover, 10 patients required surgery: amniotic membrane $(n=7)$, penetrating keratoplasty $(n=4)$, conjunctival resection $(n=3)$, tissue adhesives $(n=2)$, conjunctival flap $(n=1)$ and lamellar keratoplasty $(n=1)$.

Anti-TNF $\alpha$ drugs were the most common biologic agents used in these cases $(n=19)$ : Adalimumab (ADA) $(n=10 ; 37 \%)$, Infliximab (IFX) $(n=8 ; 29.6 \%)$ and etanercept $(n=1 ; 3.7 \%)$. In the remaining 8 cases the biologic agents were rituximab $(n=7 ; 25.9 \%)$ and tocilizumab $(n=1 ; 3.7 \%)$. The main outcome measures are summarized in the Table.

After a mean follow-up of $23.7 \pm 20$ months, all objective outcomes had improved with a reduction of the median prednisone dose from 33.7 [17.5-52.5] mg at baseline to $0[0-2.5] \mathrm{mg}(p=0.028)$. The main observed adverse effects were supraventricular tachycardia $(n=1)$ and pulmonary Tuberculosis $(n=1)$.

\begin{tabular}{|c|c|c|c|c|c|}
\hline & Basal & 1 week & 1 month & 6 months & 1 year \\
\hline $\begin{array}{c}\text { Visual acuity, } \\
\text { mean } \pm \text { SD }\end{array}$ & $0.54 \pm 0.37$ & $0.55 \pm 0.35$ & $0.58 \pm 0.33$ & $0.67 \pm 0.3^{*}$ & $0.69 \pm 0.27^{*}$ \\
\hline $\begin{array}{c}\text { Peripheral thinning } \\
\text { \# }\end{array}$ & 85.7 & $80^{*}$ & $57.1^{*}$ & $40^{*}$ & $34.3^{*}$ \\
\hline $\begin{array}{c}\text { Central keratolysis } \\
\#^{*}\end{array}$ & 17.1 & $8.6^{*}$ & $0^{*}$ & $8.6^{*}$ & $5.7^{*}$ \\
\hline $\begin{array}{c}\text { Ocular perforation } \\
\#\end{array}$ & 11.4 & $14.3^{*}$ & $0^{*}$ & $0^{*}$ & $2.8^{*}$ \\
\hline Scleritis \# & 34.3 & $22.8^{*}$ & $8.6^{*}$ & $0^{*}$ & $0^{*}$ \\
\hline Episcleritis $\#$ & 22.8 & $11.4^{*}$ & $5.7^{*}$ & $2.8^{*}$ & $2.8^{*}$ \\
\hline Uveitis \# & 14.3 & 14.3 & $8.6^{*}$ & $2.8^{*}$ & $2.8^{*}$ \\
\hline
\end{tabular}

\# Data expressed as $\%$ of the active eyes
* $p<0.05$ compared with basal data 